\title{
The EVA-based performance evaluation for Moutai in nearly three years
}

\author{
Wei Du, Yongxia Jin , Si Zhang
}

School of Management, Guangdong University of Technology, Guangzhou, CHINA

\begin{abstract}
This paper calculated the EVA index of Moutai by the method of empirical analysis. We first compare the Eva index with other similar indices and then compare the indexes of Moutai with other enterprises' indexes. Finally, the conclusion obtained is that Moutai has achieved outstanding performance in nearly three years. The company is still faced with many challenges in operations; we come up with some effective measures.
\end{abstract}

Keywords: EVA, performance measures, Moutai JEL Classification Code: D04; D46

\section{INTRODUCTION}

Fortune released the ranking of the Chinese top 500 enterprises in 2013. In the ranking of the net profit, Guizhou Moutai co., LTD, which is called Moutai for short ranked 184, and Yibin wuliangye co., LTD (Wuliangye for short)ranked 178, Luzhou laojiao co., LTD (Laojiao for short) in 347. In the list of net profit margin, Moutai rose to the first, Laojiao and Wuliangye ranked 17 th and 18th respectively. The ranking of the three companies in the list of net profit margin ascended a lot. Why the three companies' net profit margin could be so high? Why Moutai could be ranked at the top of net profit margin list?

\section{ABOUT THE EVA INDEX}

Economic value added (EVA) refers to the balance between the net operating profit after tax and the cost of capital, which has inherited the core idea of the residual income, and makes the performance evaluation be consistent with the enterprise value. That is to say, accounting profit is not real. While the profit which has cut the cost of capital is the real profit, and is called economic profit (Jiang Zhiwen, 2011). Therefore, applying the EVA index, which considers the investors' capital cost, to evaluate enterprise performance is more in line with the actual condition.

The EVA calculation dominated by Stern Stewart management consultancy adjust more than 200 items. In the actual calculation, it is not operable. Some domestic scholars in our country have also conducted similar calculations, but the methods are not all the same. In 2010, SASAC put forward an EVA calculation formula and defined the capital cost rate as $5.5 \%$ by referenced to the three-year bank benchmark lending rate (Jiang Zhiwen, 2011). In the following calculation of EVA, this paper uses the formula of SASAC. 
The formula is (Meng Jinmin, 2002): economic value added = net operating profit after tax the cost of capital = net operating profit after tax - adjusted capital * the average cost of capital rate net operating profit after tax $=$ net profit + (interest payments + the research and development expenses adjustment - non-recurring gains * 50\%) * (1 - income tax rate) adjusted capital $=$ average owners' equity + average total liabilities - average interest-free current liabilities - average construction-in-process

\section{Necessity OF USING THE Formula}

In the practice of EVA calculation, the methods of scholars in our country are not the same. Moreover, they are not universal and representative. SASAC EVA calculation method has been used in the performance evaluation of more than 20000 central enterprises. The long-term and short-term debts are few in the enterprises we discussed in this paper. Obviously, the financing cost is low. So it will not cause the exaggerated problem brought by the high actual financing cost. It is suitable to use the method of SASAC in this paper.

The calculation of EVA index of Moutai in nearly three years

\begin{tabular}{|l|l|l|l|}
\hline Name & 2011 & 2012 & 2013 \\
\hline $\begin{array}{l}\text { Net operating profit } \\
\text { after tax }\end{array}$ & $9,266,612,047$ & $14,014,825,147$ & $15,972,698,903$ \\
\hline The cost of capital & $21,718,932,267$ & $30,106,648,679$ & $45,029,593,229$ \\
\hline EVA & $8,072,070,773$ & $12,358,959,469$ & $13,496,071,276$ \\
\hline$\Delta$ EVA & - & $53.11 \%$ & $9.2 \%$ \\
\hline $\begin{array}{l}\text { Correction rate of } \\
\text { the net profit }\end{array}$ & $13 \%$ & $12 \%$ & $15 \%$ \\
\hline \multicolumn{4}{|l|}{ Note: the data from http//www.cninfo.com.cn units: yuan } \\
\hline
\end{tabular}

\section{The EXPLANATION OF THE MOUTAI EVA INDEX}

From the above table of the EVA index, the company has realized the continual three years" sustained growths in 2011-2013, which has promoted the enterprise value[4]. The considerable prime operating revenue obtained by the company are $¥ 18,402,355,207$, $¥ 26,455,335,153, ¥ 30,921,801,317$ respectively in nearly three years. Due to the uniqueness of Moutai culture, consumer demand is lack of elasticity, compared with the other liquor of the same type in the market. The alternative is weak. The enterprise fixes the higher price of Moutai products, to guarantee its considerable prime operating income. Further, because of its scarcity, the deposit received in advance is massive and brings the huge cash for the enterprise (Piao Zhefan, 2008). From the near three-year financial reporting (Zhao Zhigang, 2010), the cash and cash equivalents is $¥ 18,254,690,162$ in 2011 , the year 2012 is $¥ 22,061,999,850$, the year 2013 is $¥ 25,185,009,332$. The massive fund is the most active asset for the company and can create the investment income for the enterprise like the capital. In particular, the deposit received is interest-free liabilities, which are obtained by relying on commercial credit, and accounts for $52 \%, 43 \%$ and $44 \%$ respectively in the cash and cash equivalents. The interest income is $¥ 352,218,795$, $¥ 421,711,335 ¥ 429,509,361$ respectively in the nearly three year. The Plenty of cash inflows ensures the company's demand for capital. In nearly three years, there have been little long-term and short-term liabilities. Compared with the most high asset-liability ratio of state-owned enterprises, it not only reduces the cost of liability, a large amount of cash deposit and reinvestment also can bring the interest income, which would form the net income after offsetting the financial expense. 


\section{Explanation of the EVA IndeX AND the Measures to Cope With Changes}

In 2011-2012, $\Delta$ EVA was 53.11\%. In 2012-2013, $\Delta$ EVA was 9.2\%. In 2012, the EVA value grew rapidly, but the growth speed extremely slows down in 2013. Economic added value increases year by year, but the growth speed in 2013 dropped to 1/5 times of the value in 2012.For shareholders, this is a reversal signal which the shareholder wealth won't grow continually. For managers, this is also the company's operating reversal signal. In 2013, Liquor-making industry in China was murky, and mainly influenced by the government policy. Owning to the convention of saving proposed recently, the original consumer luxurious demand is restrained, the sales of Moutai decline. Because the company always follows the strategy with high-end products, the sale of Moutai is severely affected in the high-end and the middle-end market. And it does not have the well-known brand which the populace can afford in the low-end market. They both make the Moutai performance cannot achieve stable growth. Instead, some brands like Niulanshan erguotou which follows the route with low and middle-end products, still maintain a steady growth in the market downturn.

In our country, the high-end liquor market will be affected by the government's policy continually; The luxury consumption growth has been in the end. Besides expanding the distribution channels and lowering the price, the company should cultivate the low and middle-end brand to satisfy the mass consumption as soon as possible. Cut down the price and increase the sales. Rely on sales growth to guarantee the stability of net profit growth. The Moutai is considered as the national spirit of our country, and its culture and quality have a high reputation in the world. Moreover, the health factor of Chinese traditional liquor is not inferior to the Western liquor.

Under the condition of the domestic demand for high-end liquor crunch, it is wise to develop the international market positively to increase the volume of exports, which makeup the domestic sales volume insufficiency and solves the problem of the domestic price is limited.

\section{EVA INDEX Comparison With the Other Two ENTERPRises AND EVALUATING the Performance of Moutal}

The related indicators of EVA are listed in the following form[1][3] :

\begin{tabular}{|l|l|l|l|l|}
\hline NAME & INDEX & 2011 & 2012 & 2013 \\
\hline \multirow{2}{*}{ Laojiao } & EVA & $2,742,002,115$ & $4,113,100,443$ & $3,044,058,453$ \\
\cline { 2 - 5 } & $\Delta$ EVA & - & $50 \%$ & $-25.99 \%$ \\
\hline \multirow{3}{*}{ Wuliangye } & EVA & $5,263,331,778$ & $8,845,942,423$ & $6,444,451,214$ \\
\cline { 2 - 5 } & MEVA & - & $68.07 \%$ & $-27.15 \%$ \\
\hline \multirow{4}{*}{ Moutai } & EVA & $8,072,070,773$ & $12,358,959,469$ & $13,496,071,276$ \\
\cline { 2 - 5 } & $\Delta$ EVA & - & $53.11 \%$ & $9.2 \%$ \\
\hline \multicolumn{4}{|l|}{ Note: the data from http / www.cninfo.com.cn units: yuan } \\
\hline
\end{tabular}

The three companies' liquor quality each has its own characteristics and leads the consumption demand of Chinese liquor industry. From the EVA index above, three companies have all obtained good achievement. According to the EVA value, the successive order is Moutai, Wuliangye, Laojiao. Compared with the ranking of China top 500 enterprises, Moutai and Wuliangye reversed the order. Compared with the net profit margin ranking, Laojiao and Wuliangye reversed the order. The order of the three companies raises a lot in the net profit margin ranking. According to the EVA index calculation principle, the deposit received proportion in the cash and cash equilivalents is 
large. But the account receivable proportion in the cash and cash equilivalents are quite few. A lot of interest-free current liabilities, not only reduces the debt capital, but also saves the cost of debt capital. Furtherly, these reinvestments of the interest-free current liabilities can also create the benefits for the enterprise.

From the previous table, the EVA value of Moutai goes far beyond Wuliangye and Laojiao. Although the $\triangle$ EVA of Moutai fell by $4 / 5$ in 2013, however, the $\triangle E V A$ of Wuliangye and Laojiao appeared negative. The growth reversal began to make shareholders concern of the sustained profitability, but in the murky liquor-making industry in 2013, the EVA value of Moutai did not drop and appeared a small scale growth, compared with the other two companies. Moutai's operating performance is worth affirmative.

\section{REFERENCES}

Jiang Zhiwen. Study on Evaluation of steel listing Corporation performance based on EVA [D].Guangdong: Guangdong University of Technology.2011:52-53

Liang Jie. The research of gem listed company performance evaluation and the market value of the correlation researchBased on Eva [D].Guangdong: Guangdong University of Technology.2011: $15-20$

Meng Jinmin. The studies of enterprise performance evaluation [M]. Beijing: China financial and Economic Publishing House.2002:47-57

Piao Zhefan. The research of enterprise value evaluation theory and applications Under information disclosure [M]. Zhejiang: Zhejiang University press.2008:47-48

Zhao Zhigang. China economic added value evaluation and management [M]. Beijing: Economic Science Press.2010: 107-108 